\title{
The impact of a smartphone or tablet application on learning transfer in the field of continuing vocational training
}

Christine Hinrichsen, Mendel University, Brno, Czech Republic

\begin{abstract}
The study aimed to research the impacts of a smartphone or tablet application in the field of continuing vocational training(CVT). Well trained employees are of utmost importance in the eyes of any corporation. With the help of literature review and survey, the empirical study gets to conclude that these modes help proactively to increase learning transfer in CVT. Furthermore, the study shows that such applications are currently not yet a standard learning transfer tool.
\end{abstract}

Keywords: Evaluation of training, instruments of evaluation, CVT, HRD, ROI, VOI, lifelong learning, smartphones

JEL codes: I25, M12 


\section{Introduction}

Effective transfer of knowledge is becoming progressively significant in the arena of continuing vocational training (CVT). Moreover, the achievement of a corporation and persons will be contingent on how fast they learn, advance new, appropriate thoughts, and invest them in practice. So, CVT has to reach corporate aims. For this reason, assessment of knowledge and learning transmission is the vital charge of education monitoring (Hinrichsen, 2020).

Increased investment in continuing vocational training underlines the rising importance of employee development and training in practice (Gnefkow, 2008). In 2016, more than half of the participants in a study took part in one continuing vocational training activity (Schrader, et al., 2017). In her interpretations, (Kauffeld, 2010) highlights the significance of well-trained employees and defines them as the capital assessment of a corporation. However, well-trained employees are not sufficient to guarantee the achievement. Rather, it is essential that the recently learnt skills and capabilities of the employees can be useful in their everyday work to facilitate a prosperous learning transfer takes place. The beginning of evaluation formulates the Four-Level-Evaluation-Model established by Kirkpatrick in 1959 (George M. Alliger, 1989). It is up till now used in its necessary aspects currently. Kirkpatrick's model is protracted by additional two levels, ROI (Return on Investment) and VOI (Value on Investment) (Donovan, 2014). The fundamental facts built on algorithms for instance ROI or the expressive determination of the additional value VOI are not adequate in their significance to fulfil the regularly varying requirements to the extent of HRD (Human resource development). (Donovan, 2014) The necessity for the practice of technologies that eradicates the limitations of time and location surges little by little currently, when facts and consent to data gain significance. The consequence of smartphone and tablet learning is a concern to be investigated with the intention of its effects in continuing vocational training. The element that smartphones are portable. They have lots of features regardless of the size, which raises their curiosity for them. This growing attention needs more investigation on these phones and tablets or causes the practice of these devices in other fields. The aspect of smart devices that qualify learning atmosphere for employees reassures for their use. Moreover, it allows an instructor who shares the data to interact with more learners free of time and position with the practice of mobile devices in learning (Alkan, 2011).

The long-standing victory of a business expressively depends on whether employees efficiently and sustainably study and transmit new data in the arrangement of active work performance, cost-effective for the company. Employees' continuing learning is thus a central element of safeguarding the company's prospects (Donovan, 2014).

\subsection{Background of the study}

Around sixty years ago, Kirkpatrick issued a sequence of articles in which he defined four groups of measures of the efficiency of training effects (George M. Alliger, 1989). The Four-Level-Evaluation-Model evaluates training on four levels: $1^{\text {st }}$ level 'Reaction', $2^{\text {nd }}$ level 'Learning', $3^{\text {rd }}$ level 'Behaviour', $4^{\text {th }}$ level 'Results'. The first level 'Reaction' is the most common and frequent evaluated level (Kellner, 2006). A feedback form is used as a 
standard to evaluate this level.

The last level 'Results', measures the results generated by the participant's participation in the program. The results can for example include increased production, improved quality, and decreased costs (Donald Kirkpatrick, 2006). Baldwin and Ford's research on learning transfer extends Kirkpatrick's model. 'For the transfer to have occurred, learned behaviour must be generalized to the job context and maintained over a while on the job' (Timothy T. Baldwin, 1988).

Baldwin and Ford developed a model of transfer process:

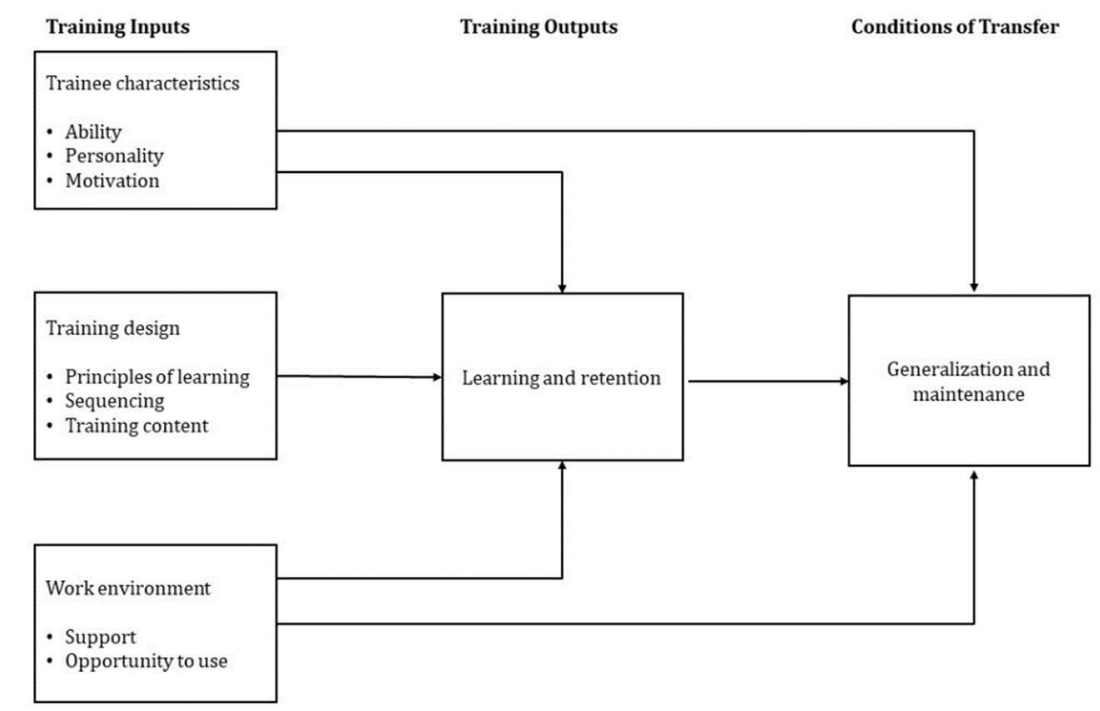

Figure 1: A model of a transfer process, Author's own illustration, adopted from Baldwin and Ford (1988)

The process-orientated model is based on the idea that learning transfer of training depends on three different categories of training input: Trainee characteristics, training design and work environment. The outcome of training is directly impacted by trainee characteristics and work environment, whereas the impact of training design depends on the levels of training outputs such as learning and retention. The sub-items mentioned in the figure above represent the transfer determinants. The model allows the use of frameworks for evaluating the impact of each input factor in training.

\subsection{Statement of the problem}

In the last 30 years, the question of transfer research has changed. Not only is the effectiveness of training evaluated, but also the reason why it works (Kauffeld, et al., 2012). Through qualitative literature research, the evaluation model in the field of continuing vocational training, which is still fundamental today, is presented. Donald Kirkpatrick developed this model more than 60 years ago. The basic features of his FourLevel-Evaluation-Model are still relevant today.

This researcher will demonstrate quite a decent knowledge on how the smartphones or tablet application on learning transfer in the field of the continuing Vocational Training. 


\subsection{Research objectives}

Through the empirical literature review and quantitative analysis accompanied by the survey. In this article, the author examines the extent to which a smartphone or tablet application can be used as a flexible tool to satisfy the demands of complex learning transfer. The focus is on transfer determinants that can be influenced by participants or managers. Furthermore, the author will investigate which of the transfer determinants are supported by using a smartphone or tablet application.

\subsection{Research questions}

Based on the reconstruction of the basic theoretical evaluation models and transfer models, the author examines the following research questions:

- To what extent can the use of a smartphone or tablet application support the communication process in terms of successful learning transfer?

- Which transfer determinants are supported using a smartphone or tablet application?

- How can technology be used effectively to enhance the maintenance of continuing vocational training?

\subsection{Hypotheses}

In the empirical study, the following will be the determining hypotheses related to the subject matter of the research:

- The relation amongst the learning modules and today's invention and in what manner it influences.

- The relation among the negative or positive effects of smart devices in CVT.

- The relation among successful learning transfer and training design.

\subsection{Scope of the study}

The author refers to the origins of this research regarding the evaluation of training with the Four-Level-Evaluation-Model. Literature research on this model has been conducted at long intervals and is summarized in this article.

In this article, the author focuses on the question posed by Ford and others under the heading 'Shifting the paradigm'. It addresses how technology can be used effectively to enhance the generalization and maintenance of linked training (J. Kevin Ford, 2018). 


\section{Literature review}

Models for learning transfer are numerous. The author refers to the results of Gnefkow. In his framework, he established some criteria to compare existing models. For Gnefkow, (Timothy T. Baldwin, 1988) transfer model is suited to identify the question of successful determinants in the field of external continuing vocational training from the participant's point of view (Gnefkow, 2008).

In the field of learning transfer research, one was able to show that this field is very complex. Multiple levels within an organization - individual, team or organization influence and are affected (Eduardo Salas, 2012).

\subsection{The surge of effective training}

The figure below gives an overview of the measures recommended by Sales to increase the effectiveness of training. The author focuses on those suggestions that can be supported by a smartphone or tablet application, for example, promote self-regulation. The complexity of learning transfer becomes clear in the discussion about an appropriate definition. Gessler proposes the term 'transformation' instead of 'transfer'.

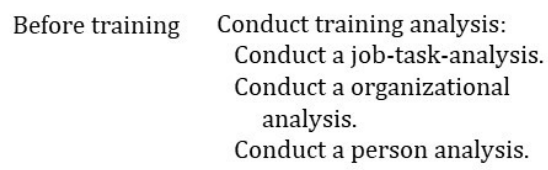

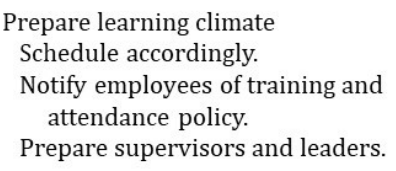

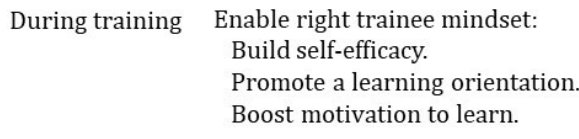

Use technology wisely:

Use computer-based training correctly.

Provide structured user control. Enhance learning through simulations.

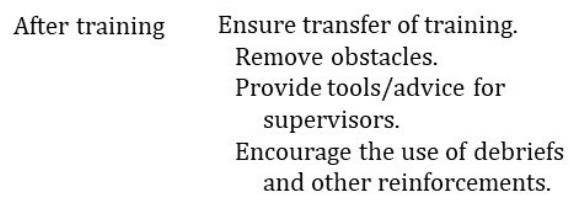

Figure 2: Evidence-based recommendations and best practices for maximizing training effectiveness, Author's illustration, adopted from Salas et al. (2012)

He argues that the movement from learning to the application does not mean knowledge is 'conveyed', 'transported' or simply 'transmitted' from the learning field to the performance field, but rather a context-based transformation of knowledge (Sandra Bohlinger, 2015).

The term 'transformation' originates from Latin and can be translated as converted, transformed, changeable. In a constantly changing world of work, the term 'transformation' in its meaning 'changeable' captures the complex requirements for learning transfer in continuing vocational training. 
From the point of view of people in organizations, training is not a single event. Rather, it is regarded as part of an episode (Baldwin, 2009). Training episodes are only one of several types of episodes (for instance re-organizations) employees experience in organizations. Thus, training can also be viewed as one stage of a longer process. A more current research approach is to examine the learning transfer already during the training accompanied by the effects created by smartphones and tablet applications. Based on an 11-day project management training, Hinrichs has developed the concept of "collateral learning transfers". This is to be interpreted as a development process in the temporal progress of the training course (Sandra Bohlinger, 2015).

Furthermore, the time factor must also be considered. Depending on the time the participant can use and deepen acquired knowledge and skills in the workplace, the transfer of learning is considered successful or not.

\subsection{Everskill Smartphone or Tablet Application}

The examined application was developed by the company 'everskill'. The company has been on the market with this application for about three years. The everskill application is a transfer program and supports the participants after their training. This application works in such a way that the participants enter a virtual training room, in which a selection of possible objectives for learning transfer is already stored. This virtual training room is only open for participants of the training. For each training, it is possible to create an individual virtual training room. Participants can either select goals from this room or define their own goals. The participant is instructed to create a routine similar to a training routine. It is possible to deposit photo protocols, seminar scripts or other documents in the virtual training room. The application reminds participants of push-up messages.

It is possible to evaluate the use of the application and obtain initial information about the status of the learning transfer. Additionally, a digital coach is implemented and answers individual questions of the users.

Furthermore, a smartphone or tablet application might help to identify what happens to the individual trainee from the time they have left the training to when one measures transfer (J. Kevin Ford, 2018).

\section{Materials and methods}

Relied on qualitative literature investigation the progress of implements for the assessment of CVT actions is recreated. The study outcomes of Kirkpatrick in 1959 are founding the commencement (George M. Alliger, 1989). The addition of Kirkpatrick's Four-Level-Evaluation Model by Phillips through an additional level is the continuance of the restoration (Donovan, 2014). The fifth level, named ROI (Return on Investment) computes and controls this important symbol in continuing vocational training. An additional leeway of evaluation CVT is the fortitude of the VOI (Value on investment). (Kellner, 2006) established in 2005 a Model of VOI founded on six stages to be handled. Nevertheless, when computing ROI in CVT numerous complications must be reflected. Computing the ROI comes to be more problematic if working out that train purported soft abilities are to be appraised. Merely restricted devices are accessible for this drive. Employee gratification can be dignified, for instance, by using surveys. Nevertheless, in 
this instance, it is not tranquil to place augmented employee gratification in a demonstrable and direct framework with computable commercial victory. The above obtainable important statistics ROI and VOI denote the subject of sustainability and efficacious learning transfer. Hypothetically is exposed to what degree the contributors can participate in an upsurge of ROI or VOI. The query of the right instrument for an efficacious learning transfer, then thus a proper instrument to degree the success of continuing vocational training, is being lectured by a wide variety of organizations and businesses. Also, the training project in the area of CVT is advanced under the feature of the provision opportunity by submission for a mobile phone or tablet. In case the application is practised harshly and sufficiently throughout the training project procedure, a momentous upsurge in learning transfer is accomplished (Hinrichsen, 2020).

\section{Methodology and data}

\subsection{Survey}

An empirical study was designed as a survey for trainers. Participants for this study were found through personal contacts, social media placement and placement in matching groups in the professional networks LinkedIn and Xing. The 25-question questionnaire gathered demographic data as well as data on the communication process, evaluation and learning transfer in the field of continuing vocational training. The survey has been conducted in the period 01-31 January 2021. The tables 1, 2 and 3 shows the demographic data of the participants. Parts of this article have already been presented at PEFnet 2020 and EAI Mobility IoT 2020.

Table 1: Participant's data

\begin{tabular}{|l|}
\hline 36 valid questionnaires \\
29 female trainers \\
7 male trainers \\
\hline
\end{tabular}


Table 2: Data collected from the survey of 36 questionnaires

\begin{tabular}{|l|l|l|l|l|l|l|l|l|}
\hline Gender & $\begin{array}{l}\text { Age } \\
\text { up to } \\
40 \\
\text { years }\end{array}$ & $\begin{array}{l}\text { Age } \\
\text { between } \\
40 \text { and } \\
64 \text { years }\end{array}$ & $\begin{array}{l}\text { Age } \\
\text { over } \\
64 \\
\text { years }\end{array}$ & $\begin{array}{l}\text { Living in } \\
\text { Germany }\end{array}$ & $\begin{array}{l}\text { Living in } \\
\text { Switzerland }\end{array}$ & Employed & Freelance & $\begin{array}{l}\text { Employed } \\
\text { and } \\
\text { Freelance }\end{array}$ \\
\hline Female & 9 & 20 & 0 & 28 & 1 & 11 & 17 & 1 \\
\hline male & 4 & 2 & 1 & 7 & 0 & 5 & 2 & 0 \\
\hline
\end{tabular}

Table 3: Data collected from the survey of 36 questionnaires

\begin{tabular}{|l|l|l|l|l|l|l|l|}
\hline Gender & $\begin{array}{l}\text { Work } \\
\text { experience } \\
\text { up to 5 } \\
\text { years }\end{array}$ & $\begin{array}{l}\text { Work } \\
\text { experience } \\
\text { between } 5 \\
\text { and } 10 \\
\text { years }\end{array}$ & $\begin{array}{l}\text { Work } \\
\text { experience } \\
\text { of more } \\
\text { than } 10\end{array}$ & $\begin{array}{l}\text { Professional } \\
\text { qualification } \\
\text { academic }\end{array}$ & $\begin{array}{l}\text { Professional } \\
\text { qualification } \\
\text { non-academic }\end{array}$ & $\begin{array}{l}\text { Smart } \\
\text { devices } \\
\text { as a } \\
\text { hurdle } \\
\text { in CVT }\end{array}$ & $\begin{array}{l}\text { Smart } \\
\text { devices } \\
\text { as not a } \\
\text { hurdle } \\
\text { in CVT }\end{array}$ \\
\hline Female & 8 & 7 & 14 & 22 & 7 & 5 & 24 \\
\hline Male & 1 & 3 & 3 & 4 & 3 & 1 & 6 \\
\hline
\end{tabular}

\subsection{Empirical study}

A whole of 36 trainers contributed to the empirical research. Of the contributing coaches, nineteen are freelancers, fourteen are employed (two did not reply to this question and one trainer works both as a freelancer and as an employee). Of the participating trainers, twenty-seven have more than five years of work experience. While the rest nine trainers have experience only up to 5 years. About 6 trainers consider smartphone and tablet applications as a hurdle in CVT. While 30 trainers consider it as not a hurdle in CVT. In the empirical study, the two basic forms of training in the field of continuing vocational training were examined: Open seminars and in-house training. In the case of open seminars, participants from different companies register for specific training on a given topic; in the case of in-house training, participants from one company are trained on a specific topic. The author focuses in her study on possible differences between employed and freelance trainers regarding evaluation or learning transfer impacted by smartphone and tablet applications. Furthermore, the study collected data on the extent to which trainers are involved in the training design process and m-learning (mobile learning).

\subsubsection{Evaluation}

Fourteen employed trainers took part in the study. The distribution of the possible evaluation instruments shows that in-house training, the verbal flashlight and feedback 
forms are used by fifty per cent of the employed trainers. A final round with the customer is used by only one-third of these trainers.

Of the eighteen freelance trainers in in-house training, fourteen use a verbal flashlight, seventeen feedback forms, and thirteen a final round with the customer. Three trainers also indicated that they use other evaluation tools such as online and offline transfer tasks, online surveys after the training, feedback interviews with managers or HR personnel.

\subsubsection{Learning Transfer}

Out of the participating fourteen employed trainers, only three trainers indicate follow up training for learning transfer in in-house training. The same applies to learning mentorships. Six employed trainers state that they have a feedback discussion with the customer, four agree on individual goals with the participants. A smartphone or tablet application is used by five trainers.

Of the eighteen freelance trainers in in-house training, fourteen use follow up training, and eleven use learning mentorships for learning transfer. A feedback session with the customer is used by eleven trainers. Ten trainers agree on individual goals with the participants. A smartphone or tablet application is used by two trainers.

\subsubsection{Communication process}

Regarding the communication process, the study focuses on in-house training. For open seminars, there is usually little communication in the run-up to the training. Open seminars are booked based on existing offers from trainers and training institutes, e.g., via the internet.

Among the permanently employed trainers, six are sometimes involved in the needs analysis of in-house training, three are mainly involved and three are fully involved. On the other hand, of the freelance trainers, nine are sometimes involved, two are mainly involved and three are fully involved.

A similar situation results in planning seminars. Here, for in-house training, five of the employed trainers are sometimes involved and seven are mainly involved. In this case, six of the freelance trainers are not involved at all, eight are sometimes involved and four are mainly involved.

This survey about the communication process also included the question of whether the trainers are aware of the objectives of the training prior to in-house training.

Here, five of the employed trainers answered that they were sometimes aware of them. Eight of them know them in most of their training. Out of the freelance trainers, the objectives are sometimes known in advance by ten trainers, six trainers answered that they mainly know the objectives before the training.

In general, employed, and freelance trainers ask participants about their goals during the training. Eleven out of fourteen employed trainers answered this question in the range sometimes too full. Seventeen out of eighteen freelance trainers answered in the above range sometimes too full. 


\section{Result}

The learning transfer's achievement is improved by the strong devising of training aims. The aims can be kept in an application. Additionally, the assessment choices of the application allow a modified training scheme. The usage of an application surges the main statistics ROI and VOI in Continuing Vocational Training.

\subsection{Kirkpatrick's Four-Level-Evaluation-Model}

The basic evaluation model is Kirkpatrick's Four-Level-Evaluation-Model. Kirkpatrick noted that the responsible person of the training program and the manager make decisions based on the results of the evaluation. For this reason, it is necessary to design, plan and implement the program carefully (Donald Kirkpatrick, 2006).

Kirkpatrick's model evaluates training on four levels:

\section{First level: Reaction}

This level measures how the participants react to the program. It is a kind of customer satisfaction survey. To measure the reaction feedback sheets are used.

\section{Second level: Learning}

Learning can be defined as the extent to which participants change their attitudes, improve knowledge, or increase skill.

\section{Third level: Behaviour}

At this level, the behaviour change is recorded. Therefore, appropriate interviews will be conducted with the participants.

\section{Fourth level: Results}

At the fourth level of evaluation, the results of the training are recorded. For example, an increase in production or reduction in costs.

Kirkpatrick assumes that these levels are linked causally. This basic evaluation model has been criticized many times. On the one hand, it is questioned whether the four levels are necessarily related. Moreover, its points of criticism demand a holistic approach (Donovan, 2014).

The fourth level is evaluating the results of the training and can be seen as a first approach to evaluate learning transfer. It can, for example, be used to measure the reduction in costs. Gessler noted that a suitable term for 'learning transfer' would be 'transformation' because learning transfer in vocational training is more like a contextbased transformation of knowledge (Sandra Bohlinger, 2015). Therefore, the Four-LevelEvaluation-Model is unsuitable for measuring learning transfer in Gessler's sense.

\subsubsection{Two research directions}

Based on Kirkpatrick's Four-Level-Evaluation-Model, two research directions have been developed. One is the outcome-oriented evaluation research, the other one is the processoriented evaluation research. In this article, the author considers process-orientated 
evaluation. Process-oriented evaluation research asks for the factors that enhance or hinder the transfer of learning (Kauffeld, et al., 2012).

\subsection{Learning transfer}

Learning is a productive procedure of performing within an atmosphere and imitating upon it. Performance embraces solving complications, engaging in discourses of enquiry and getting new information (Sharples, 2000). Moreover, the new information with the innovative smart devices like mobiles and tablets had affected the learning processes and outcomes in various prospects.

In the last 30 years, research on learning transfer has produced a large number of empirical studies. In their updated literature research, Baldwin and Ford examine several aspects. They first describe the development of empirical studies in the period 19882008 , then discuss conceptual approaches to enhance the understanding of the term 'learning transfer' and give an overview of future research questions (Gerard Paul Hodgkinson, 2012).

As seen above, here is the definition of learning transfer on which Baldwin and Ford base their transfer model, seen above: 'For the transfer to have occurred, learned behaviour must be generalized to the job context and maintained over a while' (Timothy T. Baldwin, 1988).

Baldwin and Ford's heuristic model visualizes and groups the transfer-promoting factors. The factors are divided into three groups: factors of the learners, training and workplace (Sandra Bohlinger, 2015). Gessler noted that with this model the question of how to design training cannot be answered (Sandra Bohlinger, 2015).

Dubs' model below can be used to illustrate the probable influencing factors as well as their dependencies and interactions for the transfer of training results to the workplace and acceleration of learning processes in the company (Dubs, 1990). The holistic transfer model developed by Dubs refers to in-company training.

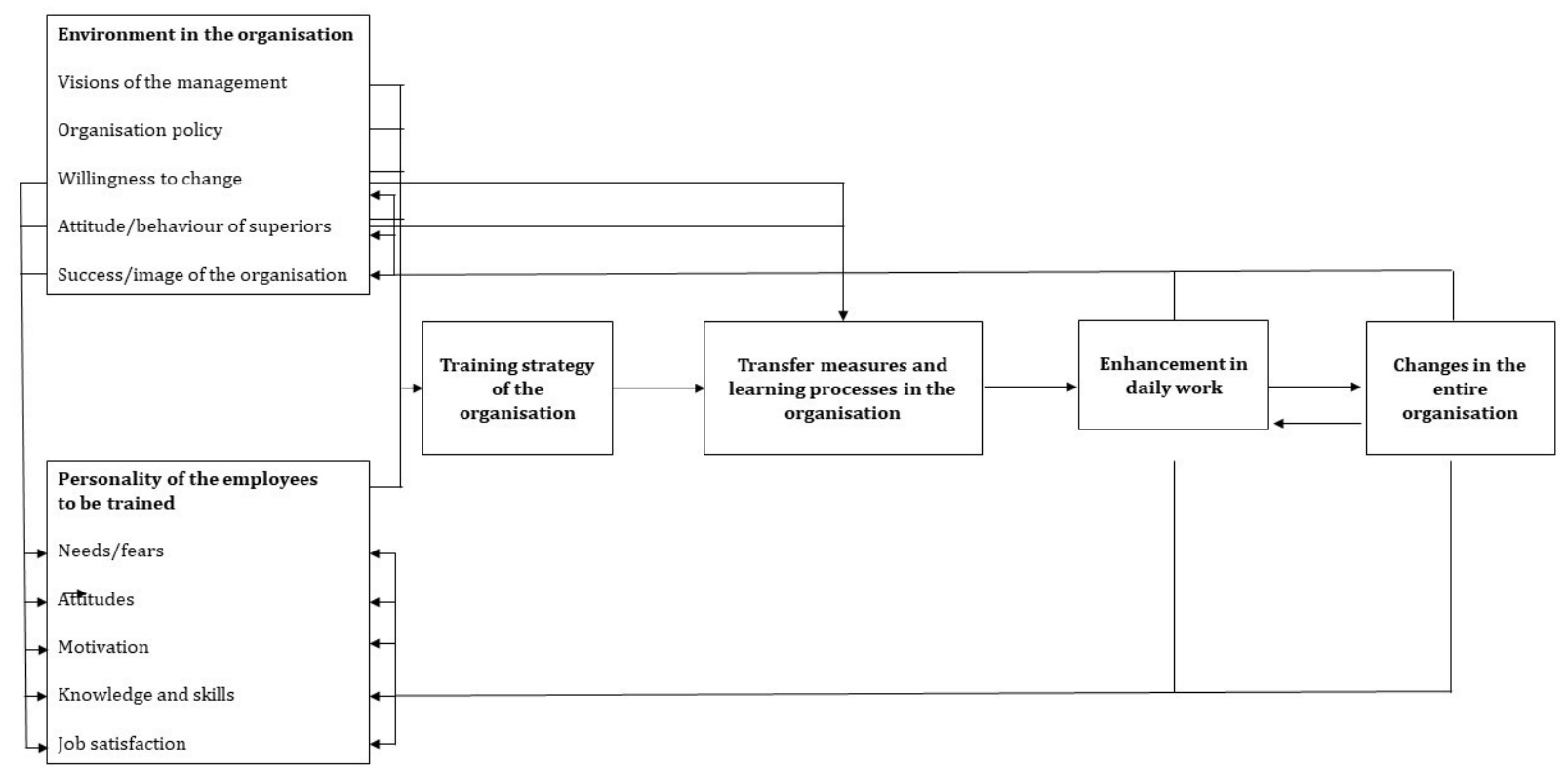

Figure 2:Transfer model Dubs, Author's own illustration, adopted from Gnefkow (2008) 
On the left side of the model, there are two categories: the first is 'environment in the organisation' and the second is 'personality of the employees to be trained'. Following to the right from these two categories in the figure are the headings 'training strategy of the organisation', 'transfer measures and learning processes in the organisation', 'enhancement in daily work' and 'changes in the entire organisation' listed. It is a closed model which is suitable for in-company training.

In distinction to Dubs, Huczynski's studies focus on the transfer variables that can be attributed to the organization (Huczynski \& Lewis, 1980). Following this approach, this model focuses on the functional field and the interaction between trainee and manager. Huczynski assigns the largest influence on learning transfer to the manager. The manager is included in all three phases of the transfer model. The transfer determinants are captured in this model. It focuses on individual transfer (Gnefkow 2008).

It should be noted that this model was only developed based on two management training. The last transfer model used by Genfkow is that of Rank/Wakenhut. Their model is also based on the framework of Baldwin and Ford and focuses on the development of transfer protection.

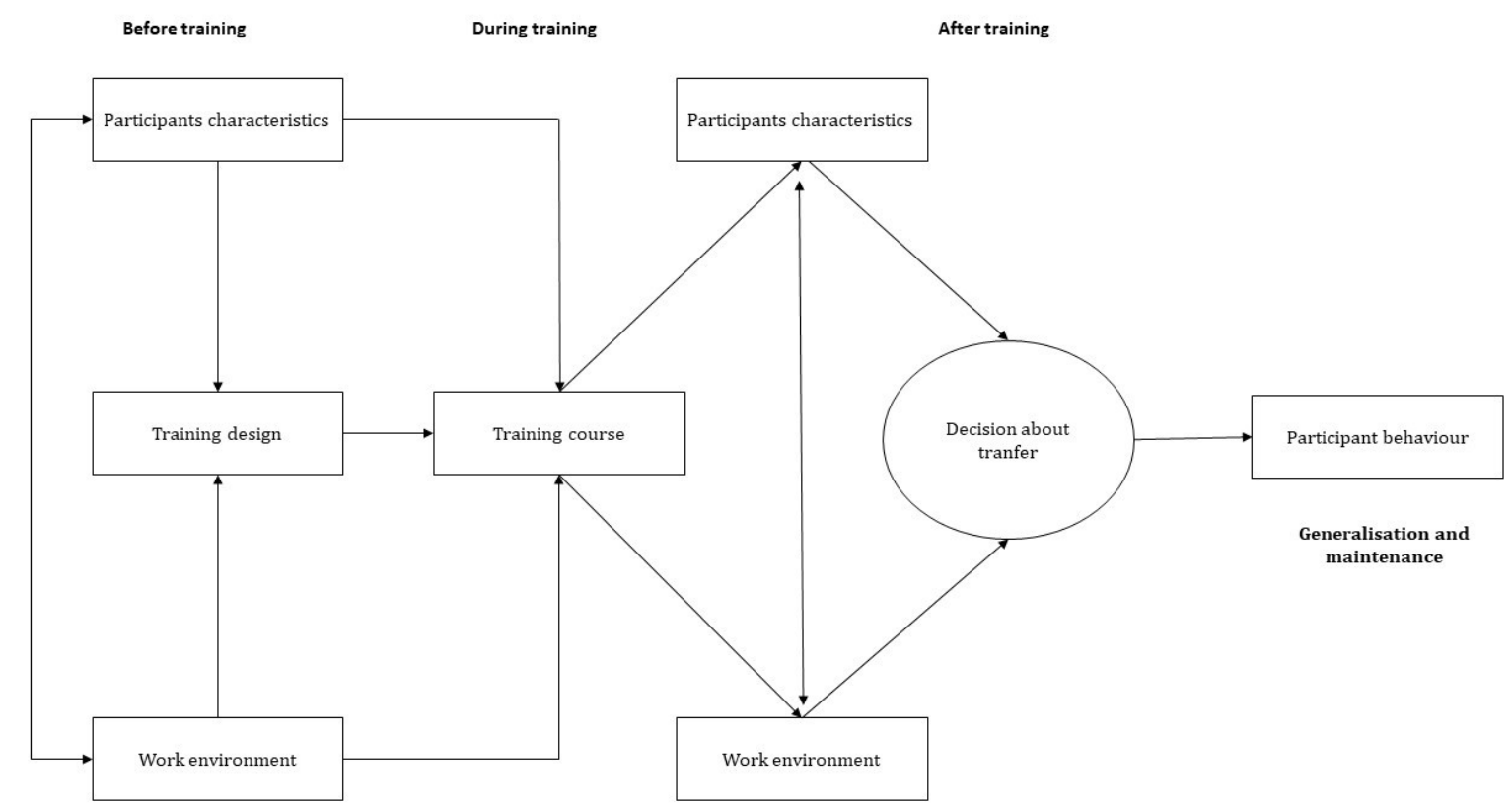

Figure 4:Integrative conditional model Rank/Wakenhut, Author's illustration, adopted from Gnefkow (2008)

The figure above shows the three phases of the transfer process (pretraining, during training, after training). Participant characteristics apply to all three phases. The ellipsis in the figure shows the focus of this model, titled 'Transfer decision'. 


\begin{tabular}{|c|c|c|c|c|}
\hline Authors/Models & Dubs & Huczynski/Lewis & Baldwin/Ford & Rank/Wakenhut \\
Criteria & - & $+/-$ & + & + \\
$\begin{array}{c}\text { Meaningful and } \\
\text { relevant categories }\end{array}$ & - & + & + & $+/-$ \\
$\begin{array}{c}\text { Simplification of } \\
\text { reality }\end{array}$ & + & - & + & + \\
$\begin{array}{c}\text { Capture of all transfer } \\
\text { determinants }\end{array}$ & + & - & + & + \\
$\begin{array}{c}\text { Clear assignment of } \\
\text { determinants }\end{array}$ & - & - & + & + \\
$\begin{array}{c}\text { Compatibility with } \\
\text { participant focus }\end{array}$ & - & $+/-$ & + & + \\
Empirical basis & - & & & + \\
\hline
\end{tabular}

Figure 3:Evaluation of the analytical framework, Author's own illustration, adopted from Gnefkow (2008)

The figure above summarises Gnefkow's findings. Baldwin and Fords' transfer model is thus the most suitable for identifying transfer determinants for successful learning transfer. Furthermore, Baldwin and Fords' model is the starting point for Gnefkow's further research. In his research, Gnefkow developed another transfer determinant, PE marketing (personnel development marketing). Gnefkow identifies this determinant as the deciding factor in affecting participant expectations and the reputation of continuing vocational training (Gnefkow, 2008).

In summary, it should be noted that there are many theoretical models of learning transfer. They are alike in their consideration of the three elementary training phases before, during and after the training and establish the most diverse relationships between the participants. The determinants developed in learning transfer research are depicted as their dependencies.

\subsection{Communication process}

The following figure shows the communication process for continuing vocational training. The communication process is divided into three phases: Pertaining phase, training phase and phase after training. Each of these phases is in turn divided into separate process steps. The pertaining phase is divided into three process steps: needs analysis, planning, and training design. The training phase consists of the process step performance of the training course. The phase after training is divided into different process steps: evaluation and learning transfer.

In the arrows next to the respective process step, the participants are listed. Here, those participants are listed who should at least be involved. For example, at least participants and, if applicable, the supervisor is involved in the needs analysis. 
The grey arrows mark those process steps within the communication process that can be influenced by a smartphone or tablet application. The functionality of the smartphone or tablet application will be described in more detail in section 2.2.

Furthermore, the author examines in the article how a smartphone or tablet application can increase the learning transfer and focuses on the aspects of goal setting in training and self-regulation of the trainees. A trainee's motivation can be enhanced through certain interventions, such as goal setting (Kauffeld, et al., 2012). The aspect of selfregulation is covered by the flexible use of the smartphone or tablet application.

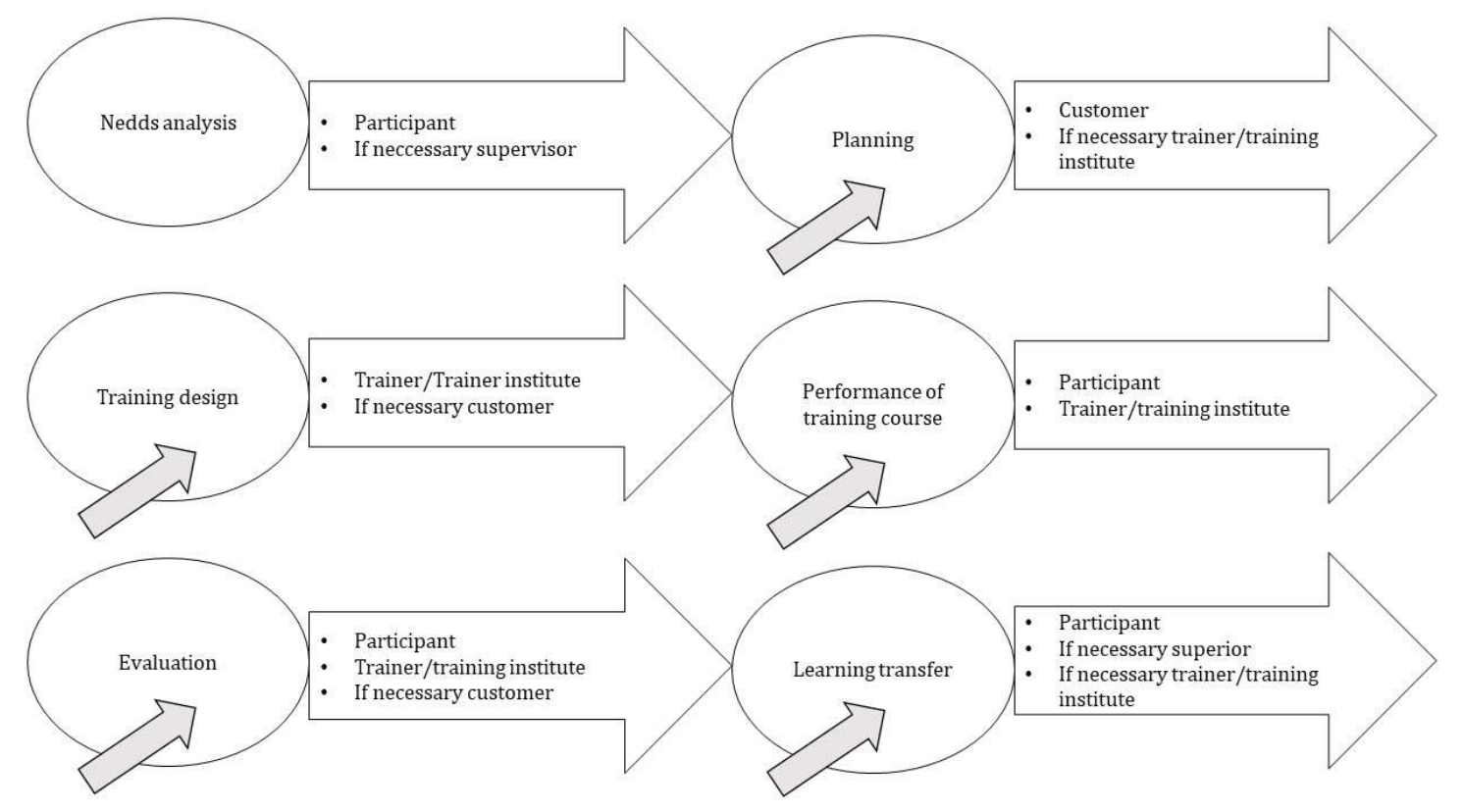

Figure 4: Communication process; Author's own illustration, adopted from Beck (2007)

\section{Discussion and Conclusion}

An analysis of the existing literature on learning transfer shows that the original models of learning transfer have been significantly developed over the last 30 years. Based on the research findings of Baldwin and Ford, further aspects have been researched on various levels. Firstly, research into the influence of the stakeholders is involved (client, supervisor, participant, trainer). Secondly, determinants have been identified that influence the transfer of learning in the categories of trainee characteristics, training design and working environment. A decisive factor for successful learning transfer is the motivation and self-regulation of the participant. A smartphone or tablet application supports this. In the presented mode of operation, it is a motivating tool that supports the independent pursuit of individual goals. Few empirical studies indicate that such an application increases motivation.

Regarding the communication process, it can be stated that a smartphone or tablet application supports this in a connecting way. If the goals of the training are already defined during the training needs analysis, the training design is adapted accordingly. 
To achieve a successful learning transfer a seamless communication process within the training design is necessary. This means that already during the needs analysis and planning of the training program all participants must be involved. It is important to define as precisely as possible how the successful learning transfer can be achieved and how it can be evaluated. The additional time required in the planning phase means that the desired training effects are closely linked to the planning and implementation of the training.

In this article, the author focuses on the effects of a smartphone or tablet application on the transfer determinants of the category participant characteristics. The use of a smartphone or tablet application directly influences six transfer determinants: extrinsic and intrinsic learning and transfer incentives, the expectation of success, prior knowledge, own initiative, and timing.

Using smartphone or tablet applications supports the communication process sustainably. The application enables to store of training goals that are individually tailored to the organization and the training program, as well as to the participants. With the functions Feed and Knowledge centre, the application also offers the possibility for participants to exchange information with each other and to store documents about the training.

Additionally, the use of an application increases the success of the learning transfer because the participants achieve a higher motivation by using the application in a selfdetermined way and putting what they have learned into practice in a goal-oriented manner.

Further work on the targeted use of different technologies should include the question of what level of acceptance a smartphone or tablet application can achieve.

The empirical study by the author has shown that there is no end-to-end communication process for in-house training and open seminars. It should be noted that this also applies as well to employed trainers.

Furthermore, there is no learning transfer process accompanying the participants until the successful implementation of the learned knowledge in their daily work. To increase learning transfer, such practice is necessary.

The graphic below shows an end-to-end learning transfer model. The connecting element is the smartphone or tablet application. The mentioned functionalities ensures that all participants are informed about the status of information and the progress of the learning transfer. This model considers objective orientation as well as an end-to-end 
communication process and is a recommendation for action for all those involved in the field of continuing vocational training.

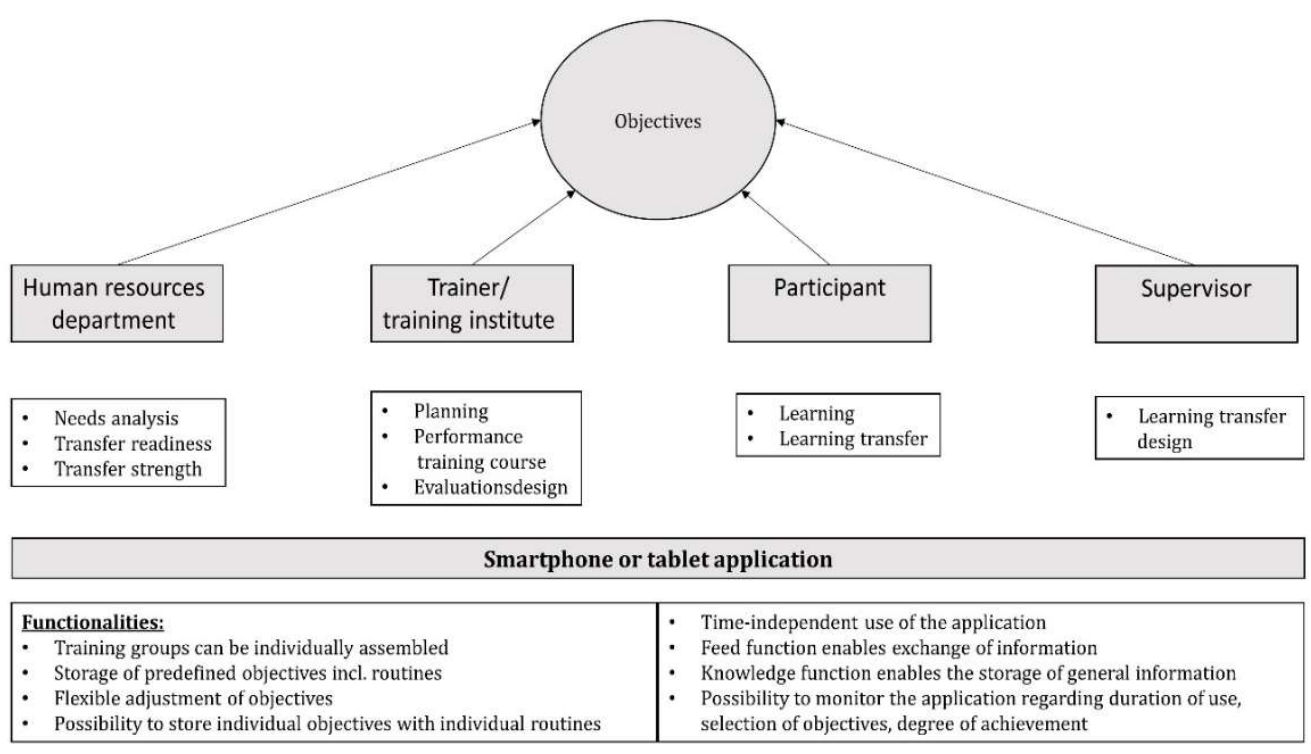

Figure 7: End-to-end learning transfer process model; Author's illustration

\subsection{Limitations and Prospects for future research}

This research study revolves around two methods i.e., literature review and survey. Unfortunately, the survey here regarding the smartphone and tablet application and its effects on CVT had a very few and the limited number of the trainer who participated in the survey.

Almost most of the empirical research have some limitations. In the maximum surveybased investigation, one is constrained by the length of the survey. Here in this study, the sample size is small, which had affected the results and outcomes of the empirical study. A sample size that's extra small decreases the supremacy of the research and surges the edge of fault, which can reduce the study pointlessly. As in this study, the researcher had to constrain to a small sample size which caused a less probable result.

Further future research studies on this subject matter should entail a larger sample size for the best probability of study results. As the empirical studies are time consuming, thus with full time and concentration the survey limitations can be resolved. Moreover, the ethical considerations play an important role. People do not always give consent for sharing their details. So, this issue must be taken into consideration by making and assuring the people to believe in the research and its purposes. 


\section{References}

ALKAN, A. T. K. A., 2011. Differences between m-learning (mobile learning) and elearning, basic terminology and usage of m-learning in education. Procedia Social and Behavioral Sciences, Volume 15, pp. 1925-1930.

ALLIGER, e. A. J., 1989. Kirkpatrick's levels of training criteria: thirty years later. Personnel psychology, pp. 1-12.

BALDWIN, F. B., 2009. Transfer of training 1988-2008: An updated review and agenda for future research. In: International Review of Industrial and Organizational Psychology 2009. s.l.:John Wiley \& Sons, pp. 41-70.

BOHLINGER, S., U. H. C. H. J. H. T. A. W., 2015. Working and Learning in Times of Uncertainty: Challenges to Adult, Professional and Vocational Education. Rotterdam, the Netherlands: Sense Publishers.

KIRKPATRICK, D., J. K., 2006. Evaluating Training Programs: The Four Levels. s.l.: BerrettKoehler Publishers.

DONOVAN, P., 2014. Training Evaluation Pocketbook: 2nd Edition. 2nd ed. Uk: Management Pocketbooks Ltd.

DONOVAN, P., 2014. Transfer of Learning in Organizations. Jens, Germany: Springer International Publishing Switzerland 2014.

DUBS, R., 1990. Lernprozesse in Unternehmungen beschleunigen. Zur

Transferproblematik in Unternehmungen. Hg. v. Nomos Verlagsgesellschaft mbH , 44(3).

EDUARDO SALAS, S. I. T. K. K. K. A. S.-J., 2012. The Science of Training and Development in Organizations: What Matters in Practice. Sage Journals, 13(2), pp. 74-101.

FORD, T. T. B. J. P., 2018. Transfer of Training: The Known and the Unknown. Annual Review of Organizational Psychology and Organizational Behavior, Volume 5, pp. 201225.

GNEFKOW, T., 2008. Transfer of learning in company further training: Determinants for the success of external company further training in the learning and functional field from a participant's perspective, Bielefeld, Germany: Bielefeld University.

HODGKINSON, J. K. F., 2012. International Review of Industrial and Organizational Psychology 2009.

HINRICHSEN, C. a. K. T., 2020. The Effects of a Smartphone or Tablet Application on Learning Transfer in Continuing Vocational Training (CVT) When Used in the Training Program. Brno, Mendel University Press, pp. 65-67.

HUCINZSKY, A. A. \& Lewis, J. W., 1980. An empirical Study into the Learning Process in Management Training. Journal of Management Studies, 17(2).

KAUFFELD, S., 2010. Sustainable training. Develop company seminars and trainings, measure success, secure transfer. Berlin: Springer-Verlag Berlin Heidelberg. 
KAUFFELD, S., Lorenzo, G. \& Weisweiler, S., 2012. Wann wird Weiterbildung nachhaltig? Erfolg und Erfolgsfaktoren beim Lerntransfer.. Hg. v. Haufe-Lexware GmbH \& Co. KG, 64(2), pp. 10-15.

KELLNER, H. J., 2006. Value of Investment: neue Evaluierungsmethoden für Personalentwicklung und Bildungscontrolling. s.l.:Offenbach : GABAL.

SCHRADER, J. et al., 2017. Weiterbildungsverhalten in Deutscland 2016, s.l.: Ergebnisse des Adult Education Survey (AES). Bielefeld: wbv (Survey - Daten und Berichte zur Weiterbildung).

SHARPLES, M., 2000. The design of personal mobile technologies for lifelong learning. Computers \& Education, 34(3-4), pp. 177-193. 